\title{
Let Food Be Thy Medicine: Diet, Nutrition, and Biomarkers' Risk of Alzheimer's Disease
}

\author{
Lisa Mosconi • Pauline F. McHugh
}

Published online: 11 January 2015

(C) Springer Science+Business Media New York 2015

\begin{abstract}
Epidemiological evidence linking diet—one of the most important modifiable lifestyle factors - and risk of Alzheimer's disease (AD) - the most common cause of dementia - is rapidly increasing. However, the biological mechanisms underlying the relationship between dietary nutrients, brain aging, and risk of $\mathrm{AD}$ are largely unexplored. Recent studies using brain imaging and biological markers of $\mathrm{AD}$ have begun to clarify how diet and nutrition modulate risk of $\mathrm{AD}$ in cognitively normal individuals, especially those at increased genetic risk. Such knowledge is critical prior to implementing dietary recommendations for prevention and treatment of disease.
\end{abstract}

Keywords Alzheimer's disease $\cdot$ Brain aging $\cdot$ Preclinical · Normal aging $\cdot$ Nutrition $\cdot$ Diet $\cdot$ Biomarkers $\cdot$ Brain imaging · Positron emission tomography $\cdot$ Magnetic resonance imaging · Plasma nutrients

This article is part of the Topical Collection on Neurological Disease and Cognitive Function

L. Mosconi • P. F. McHugh

Department of Psychiatry, New York University Langone School of Medicine, New York, NY 10016, USA

P. F. McHugh

e-mail: pauline.mchugh@nyumc.org

L. Mosconi $(\square)$

Department of Psychiatry, New York University Langone Medical

Center, 145 East 32nd St, 5th Floor, Room 505, New York, NY 10016, USA

e-mail: lisa.mosconi@nyumc.org

\section{Introduction}

Alzheimer's Disease: Facts and Figures

Alzheimer's disease (AD) is the most common form of dementia in late-life, accounting for $60-80 \%$ of cases, and the sixth leading cause of death in the United States [1]. AD is a neurodegenerative disease characterized by progressive deterioration and death of neurons, which give rise to deficits in memory, language and reasoning, and impairment of daily living activities. Currently, an estimated 5.2 million Americans of all ages have $\mathrm{AD}$. A recent report on the economic implications of the impending epidemic of $\mathrm{AD}$ indicates that, as the "baby boomer" generation ages and the population continues to increase, the number of people affected by $\mathrm{AD}$ will reach a staggering 13.8 million by 2050 in the United States alone [2, 3]. Age-related mild cognitive impairments may affect two to three times as many individuals [1]. Delaying symptoms onset by as little as 1 year could potentially lower $\mathrm{AD}$ prevalence by more than 9 million cases over the next 40 years [4].

Much effort is being devoted to the development of treatments for $\mathrm{AD}$, which is now strongly supported by the use of biological markers (biomarkers) of disease. Biomarker studies have led to a major reconceptualization of $\mathrm{AD}$, from diagnostic criteria to treatment strategies. First, the provisional diagnosis of $\mathrm{AD}$ is based on clinical history, neurological examination, cognitive testing, and structural neuroimaging [5]. However, the definitive diagnosis of $\mathrm{AD}$ is based on the postmortem detection of pathological lesions: amyloid-beta $(\mathrm{A} \beta)$ plaques in the extracellular space and blood vessels, intracellular neurofibrillary tangles, and neuronal loss in selectively vulnerable brain regions [5]. Brain imaging and other biomarkers of AD pathology are now largely being used to support the clinical diagnosis of $\mathrm{AD}$ by providing evidence for $\mathrm{AD}$ pathology in vivo $[2,3,5]$. 
For many years, the general understanding was that $\mathrm{AD}$ was a disease of old age. Recent breakthroughs in brain imaging techniques have reversed this paradigm by showing that the brain changes that lead to $\mathrm{AD}$ can be detected in predisposed individuals 20-30 years before clinical manifestations of disease become evident [6]. Brain changes in some at-risk individuals can be seen as early as infancy [7]. The early appearance of pathological lesions and the progressive nature of cognitive deterioration in $\mathrm{AD}$ led several working groups to revise the diagnostic criteria for $\mathrm{AD}$ to include in vivo biological markers of disease. This resulted in defining three stages of AD: (1) a preclinical stage of AD (no impairment in cognition; biomarker evidence for $\mathrm{AD}$, which may encompass the lifespan of the individual up until the senior years); (2) mild cognitive impairment (MCI) due to AD (impairment on memory or other domains of cognition; biomarker evidence for $\mathrm{AD}$ ); and (3) dementia due to $\mathrm{AD}$ (dementia; biomarker evidence for $\mathrm{AD}$ ) $[2,3,5]$. As discussed by Sperling et al. [3], the concept of a preclinical phase of AD should not be too foreign, because it is widely acknowledged that several illnesses, such as cancer or heart disease, can be diagnosed prior to symptoms onset by using laboratory tests or medical indicators of future disease, in a similar way that hypercholesterolemia and atherosclerosis can result in narrowing of coronary arteries that is detectable before myocardial infarction. Advances in the early detection of chronic disease are largely responsible for a true postponement of mortality and a marked change in the demographics of aging, nearly doubling the average life expectancy over the past century [8]. A similar "early detection" framework is ideally applicable to $\mathrm{AD}$, because $\mathrm{AD}$ has now the potential for being diagnosed preclinically by the use of biomarkers.

\section{Treating Alzheimer's Disease}

Currently, pharmacological treatments for AD are limited. Available medications only lessen or stabilize symptoms for a limited amount of time, and disease-modifying treatments targeting $A \beta$ removal or hindering its deposition are still under development [9]. Moreover, laboratory work and recent disappointing clinical trials raise the possibility that therapeutic interventions applied earlier in the course of $A D$ would be more likely to achieve disease modification [9]. By the time patients come in for diagnosis, too much irreversible brain damage has likely already occurred for any treatments to be effective. As such, the preclinical phase of $A D$ provides a critical opportunity for interventions that are instituted before irreversible neuronal loss, when the potential for preservation of brain function is at the greatest.

$\mathrm{AD}$ is divided in two major forms: early-onset and lateonset. The rare early-onset form of $\mathrm{AD}(\sim 1 \%$ of $\mathrm{AD}$ cases) is characterized by autosomal-dominant genetic mutations with almost complete penetrance, symptoms onset before age
60 years, and genetically induced $\mathrm{A} \beta$ overproduction [10]. Two major AD prevention initiatives are underway to test active and passive $A \beta$ immunotherapy in mutation carriers [11].

On the other hand, the most common form of late-onset $\mathrm{AD}$ (onset after age 60 years), which accounts for $>99 \%$ of the total $\mathrm{AD}$ population, is a multifactorial disease of unknown origin that most likely develops from the complex interplay between genetic and environmental factors [10]. Late-onset $\mathrm{AD}$ has been associated with several risk factors, including demographics (i.e., older age, female gender, lower education), inheritance (i.e., first-degree family history, the Apolipoprotein E, APOE, $\varepsilon 4$ allele), medical status (i.e., cardiovascular disease, hypertension), cognitive status (i.e., subjective and objective cognitive decline), environment (i.e., pollutants, environmental toxins), and lifestyle (poor diet, lack of physical or social activities, chronic stress; Table 1). The predictive value of such risk factors remains to be established, and their presence may not be enough to justify the potential risk of pharmaceutical interventions in asymptomatic individuals. There has been growing interest in identifying alternative treatment strategies that do not rely on pharmacological intervention, but rather on ameliorating individual medical and lifestyle risk factors as a way of delaying or preventing the onset of AD symptoms. Increasing evidence suggests that diet, a major modifiable lifestyle factor, may play a significant role in preventing or delaying cognitive decline and risk for dementia.

Despite studies in favor of a single or a few nutrients in the prevention of $\mathrm{AD}$, the translation to formal clinical trials testing has been largely disappointing [12-17]. For instance, prospective studies overall showed an association between higher intakes of vitamin $\mathrm{E}$ or $\alpha$-tocopherol equivalents and reduced incidence of AD [18]. However, some clinical trials showed no clinical benefits of vitamin E supplementation [15], whereas a recent double-blind, placebo-controlled, parallel-group, randomized clinical trial showed that, among patients with mild to moderate $\mathrm{AD}, 2000 \mathrm{IU} / \mathrm{d}$ of alpha tocopherol resulted in slower functional decline compared with placebo [19]. Clinical benefits were independent of treatment with memantine [19]. Likewise, despite the well-established association between B vitamins intake and lower risk of dementia [20], B vitamin supplementation did not slow cognitive decline in clinical trials of mild to moderate $\mathrm{AD}$ patients [12]. However, recent clinical trials that used biomarkers as the primary outcome showed that high-dose B vitamins supplements slowed brain atrophy rates in MCI [21, 22].

We offer that biomarkers of $\mathrm{AD}$ are the most useful measures in the short term to detect associations between dietary nutrients and AD risk and to monitor treatment efficacy, well in advance of any clinical or cognitive symptom development. Longer-term studies will be needed to determine whether the effects of dietary nutrients on $\mathrm{AD}$ biomarkers results in actual 
Table 1 Known risk factors for memory decline and Alzheimer's disease

- Age

- Family history

- Risk genes (e.g., Apolipoprotein E $\varepsilon 4$ allele, TOMM40 long variant, SORL gene)

- Female sex

- Mild cognitive impairment (especially memory)

- Past head trauma

- Poor lifestyle and heart health

- Smoking

- Poor diet (low in antioxidant rich vegetables and fruit)

- Nutritional deficiencies (e.g., vitamin $\mathrm{B}_{12}$, folate, neurotransmitter precursors, and/or catalyzers)

- Lack of exercise

- High blood homocysteine

- High blood cholesterol

- High blood triglycerides

- High blood pressure

- Poorly controlled diabetes

- Poor heart function

- Lack of lifelong intellectual activity and social engagement

- Lower education (years of schooling)

- Lack of intellectual activity

- Social isolation

disease prevention. We describe the latest research on diet, nutrition, and risk for $\mathrm{AD}$, with a particular emphasis on biomarker findings. (This article does not contain any studies with human or animal subjects performed by any of the authors.)

\section{Biomarkers of Alzheimer's Disease}

Brain imaging techniques have been developed to visualize and quantify the progressive accumulation of amyloid-beta $(\mathrm{A} \beta)$ plaques, neurofibrillary tangles, and neuronal loss that occurs during the preclinical stages of $\mathrm{AD}$, leading to changes in brain structure and function. These methods include in vivo positron emission tomography (PET) of brain A $\beta$ load and neuronal glucose metabolism, and magnetic resonance imaging (MRI) measures of structural brain volume (i.e., atrophy), perfusion, resting state connectivity, and others. Among these, structural MRI, amyloid, and metabolic PET have an established early detection potential [6] and have been used to examine diet and nutrition effects on brain $\mathrm{AD}$ biomarkers.

Not yet 10 years ago, PET tracers for fibrillar A $\beta$ (i.e., a major constituent of senile plaques) have been developed, which made the in vivo detection of AD pathology a reality. Several $A \beta$ tracers are available, including the most widely utilized $N$-methyl- $\left[{ }^{11} \mathrm{C}\right] 2-\left(4^{\prime}\right.$-methylaminophenyl)-6hydroxybenzothiazole (Pittsburgh compound-B, PiB), and the U.S. Food and Drug Administration-approved ${ }^{18} \mathrm{~F}$ Flutemetamol, ${ }^{18} \mathrm{~F}$-Florbetapir, and ${ }^{18} \mathrm{~F}$-Florbetaben [23]. These tracers bind fibrillar $A \beta$ with high affinity, showing consistently increased tracer retention in parieto-temporal, frontal, and posterior cingulate cortex of $\mathrm{AD}$ and mild cognitive impairment $(\mathrm{MCI})$ patients versus age-matched healthy controls [24-26]. Tracer retention in these regions is consistent with the distribution of $\mathrm{A} \beta$ plaques observed at postmortem [27] and predicts future decline from normal cognition to $\mathrm{AD}$ [28-30].

PET imaging with 2-[ $\left[{ }^{18} \mathrm{~F}\right]$ fluoro-2-Deoxy-D-glucose (FDG) measures resting-state cerebral metabolic rate of glucose (CMRglc), a proxy for neuronal activity [31]. AD-related synaptic dysfunction and loss induce a reduction in neuronal energy demand that results in decreased CMRglc [31]. Structural MRI is an integral part of the clinical assessment of $\mathrm{AD}$, and MRI-defined atrophy of medial temporal lobes (including hippocampus and entorhinal cortex) is now considered to be a valid diagnostic marker of early AD [32]. FDG-PET and MRI have long been used to visualize neuronal loss in $\mathrm{AD}$, which is known to originate in the medial temporal lobes during the normal stages of cognition and spread to posterior cingulate, parieto-temporal, and frontal cortices along with $\mathrm{AD}$ progression [33]. Several studies have shown progressive CMRglc reductions and atrophic changes in $\mathrm{AD}$-vulnerable regions several years prior to dementia onset [34-40].

Of great relevance to the early detection of $\mathrm{AD}$, brain biomarker abnormalities were detected in young to old individuals with risk factors for late-onset $\mathrm{AD}$, such as subjective memory decline [41, 42], a first-degree family history [43-45], and the APOE \&4 genotype [7, 46-48]. These biomarkers are therefore ideal to serve as indicators of AD risk in testing for associations between diet and $\mathrm{AD}$ risk during the preclinical phase of $\mathrm{AD}$.

\section{Diet, Nutrition, and Risk of Alzheimer's Disease}

"We are what we eat": the nutritional content of what we eat determines the composition of our cell membranes, bone marrow, blood, and hormones and therefore is the foundation upon which our body and brain are built. Whereas the importance of nutrition in health is well understood, the specific effects of nutrition on brain aging are less so, as the biological mechanisms underlying the relationship between dietary nutrients, brain aging, and AD are largely unexplored. Understanding how diet and nutrition promote healthy brain aging in people at increased risk for $\mathrm{AD}$ is critical prior to implementing dietary recommendations for prevention and treatment.

A distinction must be made between diet and nutrition; diet refers to patterns of foods eaten, whereas nutrition refers to the components of the foods that one may absorb. Most studies that looked at the associations between diet, nutrition, and $\mathrm{AD}$ 
risk have focused either on dietary patterns (i.e., food combinations) or specific dietary nutrients. Studies that reported associations between dietary nutrients and AD risk with the use of biomarkers are the main focus of this review and are discussed below (for other reviews see [20, 49-51]).

\section{Dietary Patterns}

The majority of epidemiological studies of diet and AD have focused on detecting associations between adherence to specific dietary patterns and risk of decline to AD. There is consensus that higher adherence to a Mediterranean diet (MeDi)-type pattern is associated with slower cognitive decline, reduced risk of progression from $\mathrm{MCI}$ to $\mathrm{AD}$, and reduced mortality in $\mathrm{AD}$ patients [52-56]. These effects were independent of other risk factors, including physical activity [57] and vascular comorbidity [58].

However, the biological mechanisms underlying the hypothesized brain-protective effects of the MeDi have not been clearly established. A few MRI studies reported associations between lower MeDi adherence and increased cerebrovascular disease burden (i.e., white matter lesions) in the elderly [59, 60]. A structural MRI study of cognitively normal adults showed an association between lower MeDi adherence and increased cortical thinning (i.e., atrophy) in key AD-regions, such as posterior cingulate, entorhinal, and orbitofrontal cortex [61] (Fig. 1A). Results were independent of possible risk factors for late-onset $\mathrm{AD}$, such as age, gender, education, $A P O E$ genotype, family history, as well as body max index (BMI), insulin resistance, and hypertension [61]. Overall,

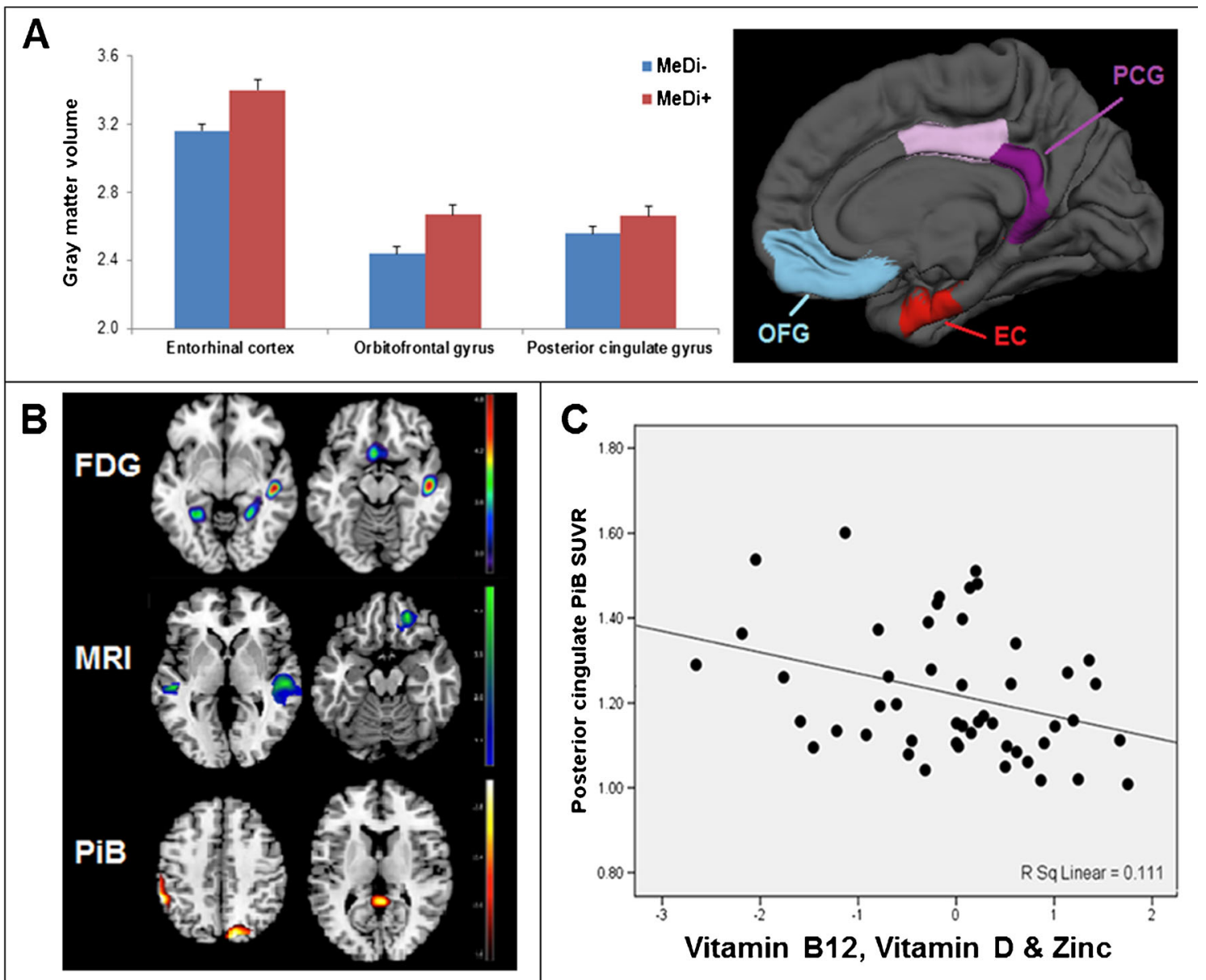

Fig. 1 Associations between dietary patterns, nutrient patterns and brain biomarkers of Alzheimer's disease. A. Left side of panel: Reduced gray matter volumes in cognitively normal (NL) individuals showing lower vs. higher adherence to a Mediterranean-diet (MeDi) pattern (MeDi- vs. $\mathrm{MeDi}+$ ), in orbitofrontal gyrus (OFG), entorhinal cortex (EC), and posterior cingulate gyrus (PCG) [61]. Right side of panel: Threedimensional representations of the three regions showing gray matter volume reductions in NL MeDi- compared with $\mathrm{MeDi}+$ (OFG, EC, PCG). Regions of interest are visible in the medial view of the gray matter surface. Only the right hemisphere is shown. B. Statistical parametric maps showing beneficial associations between intake of Vitamin B12, Vitamin D, and zinc, and three major AD biomarkers: brain glucose metabolism on FDG-PET (top), gray matter volumes on MRI (middle), and A $\beta$ load on PiB-PET (bottom). Results are represented on a color-coded scale at $p<0.001$ and displayed onto a standardized MRI. Results are adjusted for age, gender, education, BMI, APOE, family history, and total caloric intake [75]. C. Correlations between a nutrient pattern characterized by intake of Vitamin B12, Vitamin D, and zinc and $A \beta$ load in the posterior cingulate cortex of NL individuals aged 25-72 years [75] 
biomarker studies provide a pathophysiological substrate to clinical data and suggest that the MeDi may modulate AD risk through its effects on neuronal integrity. Clinical trials are needed to formally test whether MeDi interventions would result in reduced atrophy rates or other biomarkers' improvement, as well as significant reduction in, or prevention of, symptoms of cognitive decline.

Other studies used statistical models to derive food combinations associated with specific outcomes (decline to $\mathrm{AD}$ vs. stable normal cognition), without a priori selection of food groups like in the MeDi [49]. Despite differences in analytic approaches, dietary patterns characterized by higher intakes of fruits, vegetables, fish, nuts and legumes, and lower intake of meat, high-fat dairies, and sweets have been consistently associated to reduced risk for AD [49]. These findings remain to be validated by the use of biomarkers.

\section{Nutrient Patterns}

A large body of prospective studies measured dietary nutrients by means of self-reported, semiquantitative food frequency questionnaires (SFFQ), and provided evidence for associations between increased intake of omega 3 ( $\omega 3$ ) polyunsaturated fatty acids (PUFA) [62-64], B vitamins [13, 65-67], vitamins $\mathrm{A}, \mathrm{C}$, and $\mathrm{E}[18,68-70]$, various trace elements [71, 72], and better cognitive functioning or lower $\mathrm{AD}$ risk in the elderly. These clinical studies provided the basis for extending the investigation to biomarkers of $\mathrm{AD}$ to better clarify what protective effects these nutrients had on brain.

A community-based study of healthy elderly (age $>65$ years) examined plasma $A \beta 40$ and $A \beta 42$ levels and dietary intake of 10 nutrients associated with cognitive aging and $\mathrm{AD}$, including saturated fats, monounsaturated fats, $\omega-3$ and $\omega-6$ PUFA, $\beta$-carotene, vitamin B12, vitamin C, vitamin $\mathrm{D}$, vitamin $\mathrm{E}$, and folate [73]. After adjusting for age, gender, ethnicity, education, caloric intake, and $A P O E$ genotype, higher intake of $\omega 3$-PUFA was associated with lower levels of plasma $A \beta 42$ [73]. None of the other nutrients was associated with $A \beta$ measures. However, peripheral $A \beta$ measures may not be accurate indicators of $A \beta$ concentration in brain.

A brain imaging PiB- and FDG-PET study examined the associations between the same 10 nutrients as in [73], brain $A \beta$ load, and CMRglc in cognitively normal adults (mean age 54 years) with and without risk factors for AD. On PiB-PET, higher intake of vitamin $\mathrm{B}_{12}$, vitamin $\mathrm{D}$, and w3-PUFA was associated with lower $A \beta$ load in posterior cingulate, parietotemporal and frontal regions [74••]. On FDG-PET, higher intake of $\beta$-carotene and folate was associated with higher CMRglc in $\mathrm{AD}$-vulnerable regions, whereas higher consumption of saturated fats was associated with reduced CMRglc [74••]. A significant impact of risk factors, such as gender, $A P O E$, and family history, was noted on the associations between nutrients and CMRglc. Specifically, women, individuals with positive family history, and $A P O E \varepsilon 4$ carriers showed stronger associations between CMRglc and nutrient intake than their risk-free counterparts [74*0]. These results suggest that genetic risk in conjunction with unhealthy eating habits may potentiate genetic predisposition. On the other hand, the association between $\mathrm{A} \beta$ load and dietary nutrients was not exacerbated in presence of these risk factors, although this may vary in older populations with more substantial $A \beta$ deposition.

Given the interactive nature of nutrient action and cellular metabolism, principal component analysis (PCA) has been used to generate nutrient patterns (NPs), which capture the interactive effect of nutrients in combination. Multimodality brain imaging studies tested PCA-derived NPs for associations with $\mathrm{A} \beta$ deposition on PiB-PET, CMRglc on FDG-PET, and gray matter volumes (GMV) on MRI in 25- to 72-year-old cognitively normal adults [75]. Five distinct NPs were extracted from a panel of 35 nutrients related to $\mathrm{AD}$ or cognitive function. A first NP characterized by intake of vitamin $B_{12}$, vitamin $D$, and zinc was favorably associated with all biomarkers, in that the higher intake of these nutrients, the lower $\mathrm{A} \beta$ load, and the higher CMRglc and GMV in AD-vulnerable regions (Fig. 1B and C). Additionally, CMRglc and GMV were negatively associated with a second NP characterized by intake of saturated, trans-saturated fats, cholesterol, and sodium. Finally, CMRglc was positively associated with two additional NPs: one characterized by intake of vitamin E, $\omega-3$, and $\omega-6$ PUFA, and the other by intake of vitamin $A$, vitamin $C$, several carotenoids ( $\alpha$ - and $\beta$-carotene, $\beta$-cryptoxanthin, lutein, zeaxanthin), and dietary fibers [75]. The identified "brain-protective" NPs were correlated to higher intake of vegetables, fruit, whole grains, fish, low fat dairies, and nuts, and lower intake of sweets, fried potatoes, processed meat, high-fat dairies, and butter [75] (Fig. 2).

These findings are consistent with previous epidemiological and animal studies showing brain-supporting effects of the NPs identified by the use of biomarkers. The NP associated with all biomarkers included neuroprotective vitamin $\mathrm{B}_{12}[13$, 65-67], vitamin D [76, 77], and zinc, one of the most important transitional metals for human metabolism that is involved in $A \beta$ adhesiveness and amyloid precursor protein synthesis [78]. Higher intake of saturated and trans-fats was associated with reduced CMRglc and GMV, consistent with the notion that "bad fats" have negative effects on cognitive function [62, 79]. CMRglc was positively associated with intake of vitamin E, an anti-oxidant, $\omega-3$ and $\omega-6$ PUFA, which are known for their neuroprotective properties through anti-inflammatory, antioxidant, and energy metabolism pathways [80]. CMRglc also was positively associated with intake of vitamins A and $\mathrm{C}$, several carotenes, and dietary fibers. These nutrients are known to have beneficial effects via their antioxidant and $A \beta$ anti-oligomerization effects $[81,82]$ and dietary fibers help to regulate glucose levels [83]. 


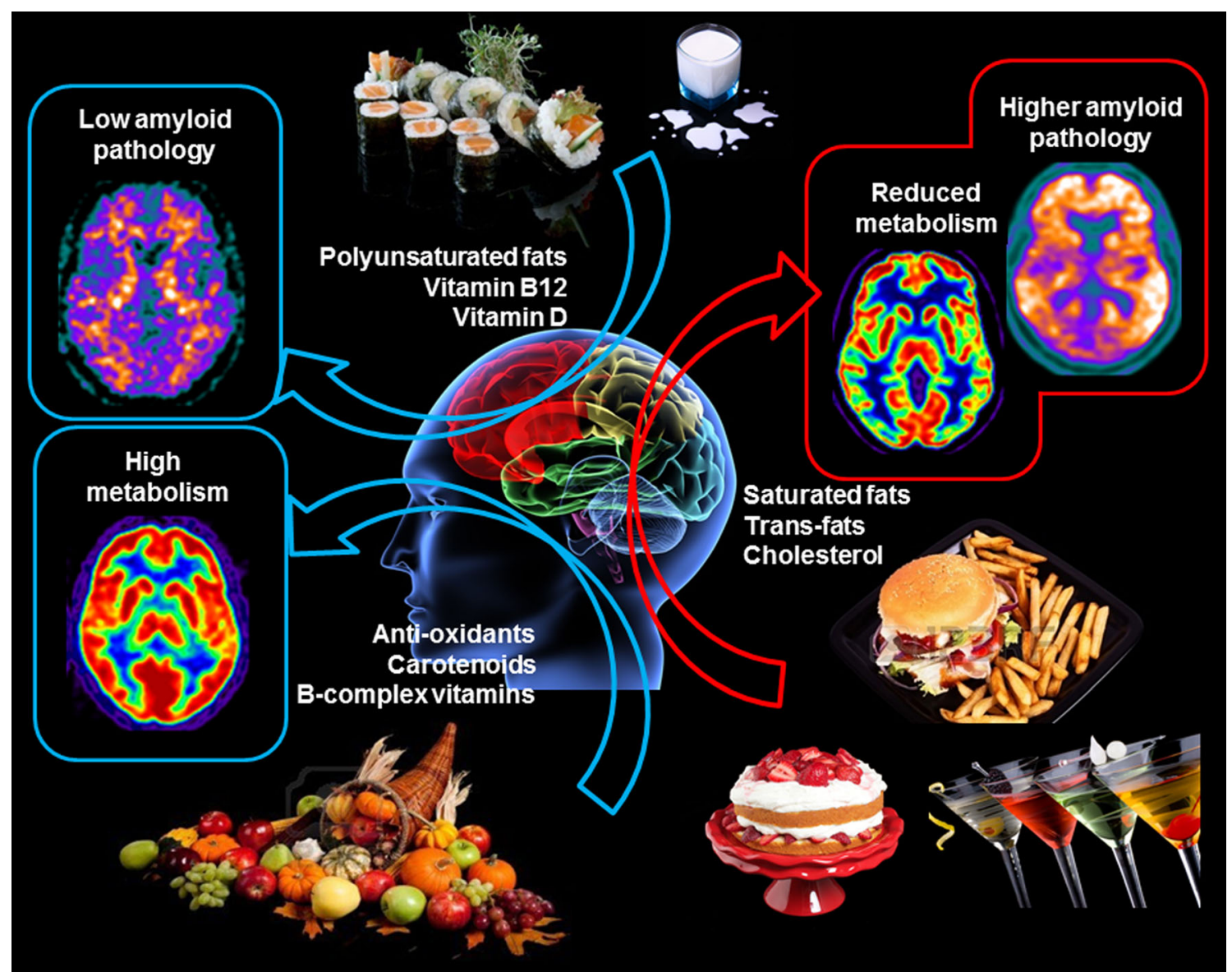

Fig. 2 Neuronutrition. Hypothetical model of brain-protective nutritional recommendations resulting from available research studies of linking dietary patterns, nutrients and biomarkers of $\mathrm{AD}$ in cognitively normal adults

A limitation to the above studies is that nutrient intake was estimated based on SFFQs. SFFQs have become a wellaccepted method for assessment of usual food choices and nutrient intake and have been validated for determination of nutrient intake in the elderly and young adults [84-86]. However, this method may not provide the necessary precision to accurately estimate the intake of specific nutrients, as it is subject to faulty recall of dietary intake and portion size, often estimated over a long amount of time such as over the prior year. Direct, quantitative measurements of plasma nutrients are better suited to provide quantitative and reliable measures of bioavailable macro- and micronutrient levels. For instance, vitamin $\mathrm{B}_{12}$ intake may be challenging to characterize by dietary intake assessment as its serum level can be affected by gastrointestinal malabsorption syndromes, such as those seen with pernicious anemia, Crohn's disease, or gastric bypass surgery; by excessive alcohol intake; or by common medications, including antacids and antidiabetic agents. Likewise, a significant component to vitamin D serum levels is sunlight exposure as well as dietary intake. Malabsorption syndromes may also affect vitamin D bioavailability, as well as conditions, such as obesity or renal insufficiency, which may interfere with vitamin $\mathrm{D}$ extraction or conversion to its active form.

\section{Plasma Nutrients}

Very few studies examined the relationships between plasma nutrients and brain biomarkers of $\mathrm{AD}$ in NL individuals. A cross-sectional MRI study looked at plasma nutrient patterns in NL elderly of fairly advanced age ( $>85$ years) [87॰]. Two plasma PCA-derived NPs associated with more favorable cognitive and MRI measures were identified: one NP high in plasma B vitamins (B1, B2, B6, folate, and B12), vitamin C, vitamin $\mathrm{D}$, and vitamin $\mathrm{E}$; and another NP high in plasma w3PUFA. Higher intake of these nutrients was associated with better executive and visuospatial function, larger brain volumes, and lower cerebrovascular burden [87॰]. A third NP characterized by high plasma trans-fat levels was associated with less favorable cognitive function and reduced brain volume [84].

A few longitudinal MRI studies investigated the associations between plasma $\omega 3$-PUFA and brain volumes in nondemented elderly, showing a strong correlation between higher baseline $\omega 3$-PUFA levels and lower atrophy rates up to 8 years later, especially in medial temporal lobes [88-90].

Given the strong associations between plasma nutrients and MRI changes, a recent randomized, double-blind, controlled 
trial of high-dose B vitamins supplementation (vitamin B6, B9, $\mathrm{B} 12$ ) in MCI patients focused on the change in MRI volumes as the primary outcome $[21,22]$. The treated group showed lower rates of whole brain atrophy over 2 years compared with placebo [22]. The treatment response was somewhat confined to participants with high homocysteine $(>13 \mu \mathrm{mol} / \mathrm{L})$, who showed $53 \%$ lower atrophy rates compared to placebo [22]. A follow-up study demonstrated that the B-vitamin treatment reduced, by as much as sevenfold, the cerebral atrophy in brain regions specifically vulnerable to $\mathrm{AD}$, such as the medial temporal lobe [21]. A causal Bayesian network analysis indicated the following chain of events: B vitamins lowered homocysteine, which directly led to a decrease in atrophy rates over 2 years, thereby slowing cognitive decline [21]. It remains to be determined whether $\mathrm{B}$ vitamins would be beneficial to patients with normal homocysteine levels and whether lowering homocysteine would reduce brain atrophy rates in cognitively normal elderly, thus prior to the relatively late MCI stage of AD. Nutritional supplementation may have stronger effects on $A \beta$ deposition or metabolic activity, which are altered prior to structural changes in $\mathrm{AD}[6]$.

A 4-week randomized, controlled, clinical trial tested the effects of a high-saturated fat/high-glycemic index (HIGH) versus a low-saturated fat/low-glycemic index (LOW) diet on cerebrospinal fluid (CSF) A $\beta$ levels and cognition in healthy elderly and MCI patients[91]. The LOW diet improved delayed visual memory and increased $\mathrm{A} \beta 42$ concentration in MCI [91], contrary to the pathologic pattern of lowered CSF A 342 typically observed in AD. For both MCI and controls, the HIGH diet increased and the LOW diet decreased plasma lipids, insulin, and CSF F2-isoprostane concentrations (i.e., a marker of inflammation) [91].

\section{Conclusions}

$\mathrm{AD}$ has been reconceptualized as a potentially preventable illness. Because pharmacological treatments are limited, there is increasing interest in implementing brain-protective lifestyle changes during the preclinical phase of AD. AD biomarkers are useful tools to examine the effects of lifestyle on AD-risk prior to irreversible neuronal loss and subsequent onset of clinical symptoms, at a time when the potential for disease modification is the greatest.

A growing body of literature provides evidence for dietary and nutrient patterns associated with biomarkers of AD risk, thus indicating that dietary nutrients may modulate AD-risk and cognitive performance through their effects on $A \beta$ deposition and associated neuronal injury several years prior to possible symptoms onset. Longitudinal studies with larger samples are needed to elucidate the molecular mechanisms through which dietary nutrients modulate AD risk, as well as to provide preliminary data for much needed clinical trials that will capitalize on the use of biomarkers. While early clinical trial results were largely disappointing, recent trials in $\mathrm{MCI}$ patients provided encouraging evidence that dietary interventions can affect AD pathology. Homocysteine-lowering $\mathrm{B}$

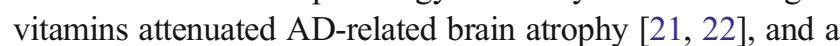
low saturated fat/glycemic index diet improved $\mathrm{A} \beta \mathrm{CSF}$ composition in MCI patients at high risk for AD [91]. Inflammatory markers offer another interesting target for clinical trials, because there is increasing recognition that low levels of systemically increased inflammation associated with negative lifestyle habits promote AD pathology and cognitive decline [92-94].

Future clinical trials will need to take into account the participants' intellectual and physical activity levels, because these lifestyle factors have been consistently associated with increased physical and mental health throughout life and reduced risk of AD [95-97].

Finally, biochemical individuality is another concept of great relevance [98]. Because we are all genetically and biologically unique, no one treatment or intervention may work for everybody. Personalized medicine will likely be most useful to assess specific individual risk factors for $\mathrm{AD}$, especially modifiable ones, such as nutrition and other lifestyle factors. Addressing these risk factors early may go a long way towards disease delay or prevention, thus greatly reducing the cost of $\mathrm{AD}$, both in terms of health care spending and in human suffering.

In conclusion, current studies support further exploration of dietary behaviors and nutritional status for the prevention of AD. Evidence for an association between poor nutritional status and increased neuronal vulnerability during aging could open up new avenues for future investigations of nutritional interventions decades prior to possible $\mathrm{AD}$ symptoms, with immediate impact on national health and clinical practice. A major goal in $\mathrm{AD}$ research will be to define dietary and nutritional patterns that promote cognitive health $[99,100 \bullet]$, in the same manner that dietary approaches for hypertension have been derived [101]. We offer that developing brainhealthy eating patterns is key to successful aging. Nutritional recommendations that are focused on supporting brain and cognitive function are sorely needed for the prevention of agerelated diseases like $\mathrm{AD}$.

Acknowledgments This work was supported by National Institute of Health/National Institute on Aging grant AG035137 and funding from New York University Langone Medical Center.

\section{Compliance with Ethics Guidelines}

Conflict of Interest Lisa Mosconi and Pauline F. McHugh declare that they have no conflict of interest.

Human and Animal Rights and Informed Consent This article does not contain any studies with human or animal subjects performed by any of the authors. 


\section{References}

Papers of particular interest, published recently, have been highlighted as:

- Of importance

-. Of major importance

1. Brookmeyer R, Evans DA, Hebert L, Langa KM, Heeringa SG, Plassman BL, et al. National estimates of the prevalence of Alzheimer's disease in the United States. Alzheimers Dement. 2011;7:61-73.

2. Carrillo MC, Dean RA, Nicolas F, Miller DS, Berman R, Khachaturian Z, et al. Revisiting the framework of the National Institute on Aging-Alzheimer's Association diagnostic criteria. Alzheimers Dement. 2013;9:594-601.

3. Sperling RA, Karlawish J, Johnson KA. Preclinical Alzheimer disease-the challenges ahead. Nat Rev Neurol. 2013;9:54-8.

4. Barnes DE, Yaffe K. The projected effect of risk factor reduction on Alzheimer's disease prevalence. Lancet Neurol. 2011;10:81928.

5. McKhann GM, Knopman DS, Chertkow H, Hyman BT, Jack Jr $\mathrm{CR}$, Kawas $\mathrm{CH}$, et al. The diagnosis of dementia due to Alzheimer's disease: recommendations from the National Institute on Aging-Alzheimer's Association workgroups on diagnostic guidelines for Alzheimer's disease. Alzheimers Dement. 2011;7:263-9.

6. Jack Jr CR, Knopman DS, Jagust WJ, Shaw LM, Aisen PS, Weiner MW, et al. Hypothetical model of dynamic biomarkers of the Alzheimer's pathological cascade. Lancet Neurol. 2010;9: $119-28$.

7. Dean 3rd DC, Jerskey BA, Chen K, Protas H, Thiyyagura P, Roontiva A, et al. Brain differences in infants at differential genetic risk for late-onset Alzheimer disease: a cross-sectional imaging study. JAMA Neurol. 2014;71:11-22.

8. Vaupel JW. Biodemography of human ageing. Nature. 2010;464: 536-42.

9. Langbaum JB, Fleisher AS, Chen K, Ayutyanont N, Lopera F, Quiroz YT, et al. Ushering in the study and treatment of preclinical Alzheimer disease. Nat Rev Neurol. 2013;9:371-81.

10. Tanzi RE, Bertram L. New frontiers in Alzheimer's disease genetics. Neuron. 2001;32:181-4.

11. Reiman EM, Langbaum JB, Fleisher AS, Caselli RJ, Chen K, Ayutyanont N, et al. Alzheimer's Prevention Initiative: a plan to accelerate the evaluation of presymptomatic treatments. J Alzheimers Dis. 2011;26 Suppl 3:321-9.

12. Aisen PS, Schneider LS, Sano M, Diaz-Arrastia R, van Dyck CH, Weiner MF, et al. High-dose B vitamin supplementation and cognitive decline in Alzheimer disease: a randomized controlled trial. JAMA. 2008;300:1774-83.

13. Ford AH, Flicker L, Alfonso H, Thomas J, Clarnette R, Martins R, et al. Vitamins $\mathrm{B}(12), \mathrm{B}(6)$, and folic acid for cognition in older men. Neurology. 2010;75:1540-7.

14. Kang JH, Cook N, Manson J, Buring JE, Grodstein F. A randomized trial of vitamin $\mathrm{E}$ supplementation and cognitive function in women. Arch Intern Med. 2006;166:2462-8.

15. Petersen RC, Thomas RG, Grundman M, Bennett D, Doody R, Ferris S, et al. Vitamin E and donepezil for the treatment of mild cognitive impairment. N Engl J Med. 2005;352:2379-88.

16. Quinn JF, Raman R, Thomas RG, Yurko-Mauro K, Nelson EB, Van Dyck C, et al. Docosahexaenoic acid supplementation and cognitive decline in Alzheimer disease: a randomized trial. JAMA. 2010;304:1903-11.

17. Morris MC, Tangney CC. A potential design flaw of randomized trials of vitamin supplements. JAMA. 2011;305:1348-9.
18. Morris MC, Evans DA, Tangney CC, Bienias JL, Wilson RS, Aggarwal NT, et al. Relation of the tocopherol forms to incident Alzheimer disease and to cognitive change. Am J Clin Nutr. 2005;81:508-14

19. Dysken MW, Sano M, Asthana S, Vertrees JE, Pallaki M, Llorente $\mathrm{M}$, et al. Effect of vitamin $\mathrm{E}$ and memantine on functional decline in Alzheimer disease: The TEAM-AD VA cooperative randomized trial. JAMA. 2014;311:33-44.

20. Morris MC, Schneider JA, Tangney CC. Thoughts on B-vitamins and dementia. J Alzheimers Dis. 2006;9:429-33.

21. Douaud G, Refsum H, de Jager CA, Jacoby R, Nichols TE, Smith SM, et al. Preventing Alzheimer's disease-related gray matter atrophy by B-vitamin treatment. Proc Natl Acad Sci U S A. 2013;110:9523-8.

22. Smith AD, Smith SM, de Jager CA, Whitbread P, Johnston C, Agacinski G, et al. Homocysteine-lowering by B vitamins slows the rate of accelerated brain atrophy in mild cognitive impairment: a randomized controlled trial. PLoS One. 2010;5:e12244.

23. Zhu L, Ploessl K, Kung HF. Chemistry. Expanding the scope of fluorine tags for PET imaging. Science. 2013;342:429-30.

24. Barthel H, Gertz HJ, Dresel S, Peters O, Bartenstein P, Buerger K, et al. Cerebral amyloid-beta PET with florbetaben $(18 \mathrm{~F})$ in patients with Alzheimer's disease and healthy controls: a multicentre phase 2 diagnostic study. Lancet Neurol. 2011;10:424-35.

25. Klunk WE, Engler H, Nordberg A, Wang Y, Blomqvist G, Holt DP, et al. Imaging brain amyloid in Alzheimer's disease with Pittsburgh Compound-B. Ann Neurol. 2004;55:306-19.

26. Rowe CC, Ackerman U, Browne W, Mulligan R, Pike KL, $\mathrm{O}^{\prime}$ Keefe $\mathrm{G}$, et al. Imaging of amyloid beta in Alzheimer's disease with 18F-BAY94-9172, a novel PET tracer: proof of mechanism. Lancet Neurol. 2008;7:129-35.

27. Braak H, Braak E. Neuropathological stageing of Alzheimerrelated changes. Acta Neuropathol. 1991;82:239-59.

28. Morris JC, Roe CM, Grant EA, Head D, Storandt M, Goate AM, et al. Pittsburgh compound B imaging and prediction of progression from cognitive normality to symptomatic Alzheimer disease. Arch Neurol. 2009;66:1469-75.

29. Mintun MA, Larossa GN, Sheline YI, Dence CS, Lee SY, Mach $\mathrm{RH}$, et al. [11C]PIB in a nondemented population: potential antecedent marker of Alzheimer disease. Neurology. 2006;67:446-52.

30. Doraiswamy PM, Sperling RA, Coleman RE, Johnson KA, Reiman EM, Davis MD, et al. Amyloid-beta assessed by florbetapir F 18 PET and 18-month cognitive decline: a multicenter study. Neurology. 2012;79:1636-44.

31. Mosconi L. Glucose metabolism in normal aging and Alzheimer's disease: Methodological and physiological considerations for PET studies. Clin Transl Imaging . 2013;1:217-233.

32. Frisoni GB, Fox NC, Jack Jr CR, Scheltens P, Thompson PM. The clinical use of structural MRI in Alzheimer disease. Nat Rev Neurol. 2010;6:67-77.

33. Morrison JH, Hof PR. Life and death of neurons in the aging brain. Science. 1997;278:412-9.

34. de Leon MJ, Convit A, Wolf OT, Tarshish CY, DeSanti S, Rusinek $\mathrm{H}$, et al. Prediction of cognitive decline in normal elderly subjects with 2-[(18)F]fluoro-2-deoxy-D-glucose/ poitron-emission tomography (FDG/PET). Proc Natl Acad Sci U S A. 2001;98:10966-71.

35. Holland D, Brewer JB, Hagler DJ, Fennema-Notestine C, Dale AM. Subregional neuroanatomical change as a biomarker for Alzheimer's disease. Proc Natl Acad Sci U S A. 2009;106: 20954-9.

36. Jack Jr CR, Lowe VJ, Weigand SD, Wiste HJ, Senjem ML, Knopman DS, et al. Serial PIB and MRI in normal, mild cognitive impairment and Alzheimer's disease: implications for sequence of pathological events in Alzheimer's disease. Brain. 2009;132: $1355-65$. 
37. Jagust W, Gitcho A, Sun F, Kuczynski B, Mungas D, Haan M. Brain imaging evidence of preclinical Alzheimer's disease in normal aging. Ann Neurol. 2006;59:673-81.

38. Mosconi L, De Santi S, Li J, Tsui WH, Li Y, Boppana M, et al. Hippocampal hypometabolism predicts cognitive decline from normal aging. Neurobiol Aging. 2008;29:676-92.

39. Mosconi L, Sorbi S, de Leon MJ, Li Y, Nacmias B, Myoung PS, et al. Hypometabolism exceeds atrophy in presymptomatic earlyonset familial Alzheimer's disease. J Nucl Med. 2006;47:1778-86.

40. Mosconi L, Mistur R, Switalski R, Tsui WH, Glodzik L, Li Y, et al. FDG-PET changes in brain glucose metabolism from normal cognition to pathologically verified Alzheimer's disease. Eur J Nucl Med Mol Imaging. 2009;36:811-22.

41. Perrotin A, Mormino EC, Madison CM, Hayenga AO, Jagust WJ. Subjective cognition and amyloid deposition imaging: a Pittsburgh Compound B positron emission tomography study in normal elderly individuals. Arch Neurol. 2012;69:223-9.

42. Scheef L, Spottke A, Daerr M, Joe A, Striepens N, Kolsch H, et al. Glucose metabolism, gray matter structure, and memory decline in subjective memory impairment. Neurology. 2012;79:1332-9.

43. Mosconi L, Brys M, Switalski R, Mistur R, Glodzik L, Pirraglia E, et al. Maternal family history of Alzheimer's disease predisposes to reduced brain glucose metabolism. Proc Natl Acad Sci U S A. 2007;104:19067-72.

44. Mosconi L, Mistur R, Switalski R, Brys M, Glodzik L, Rich K, et al. Declining brain glucose metabolism in normal individuals with a maternal history of Alzheimer disease. Neurology. 2009;72:513-20.

45. Mosconi L, Rinne JO, Tsui WH, Berti V, Li Y, Wang H, et al. Increased fibrillar amyloid-\{beta $\}$ burden in normal individuals with a family history of late-onset Alzheimer's. Proc Natl Acad Sci U S A. 2010;107:5949-54.

46. Reiman EM, Caselli RJ, Chen K, Alexander GE, Bandy D, Frost $\mathrm{J}$. Declining brain activity in cognitively normal apolipoprotein $\mathrm{E}$ epsilon 4 heterozygotes: A foundation for using positron emission tomography to efficiently test treatments to prevent Alzheimer's disease. Proc Natl Acad Sci U S A. 2001;98:3334-9.

47. Reiman EM, Chen K, Alexander GE, Caselli RJ, Bandy D, Osborne D, et al. Functional brain abnormalities in young adults at genetic risk for late-onset Alzheimer's dementia. Proc Natl Acad Sci U S A. 2004;101:284-9.

48. Reiman EM, Chen K, Liu X, Bandy D, Yu M, Lee W, et al. Fibrillar amyloid-beta burden in cognitively normal people at 3 levels of genetic risk for Alzheimer's disease. Proc Natl Acad Sci U S A. 2009;106:6820-5.

49. Gu Y, Scarmeas N. Dietary patterns in Alzheimer's disease and cognitive aging. Curr Alzheimer Res. 2011;8:510-9.

50. Morris MC, Tangney CC. Dietary fat composition and dementia risk. Neurobiol Aging. 2014;35S2:S59-64.

51. Gu Y, Luchsinger JA, Stern Y, Scarmeas N. Mediterranean diet, inflammatory and metabolic biomarkers, and risk of Alzheimer's disease. J Alzheimers Dis. 2010;22:483-92.

52. Feart C, Samieri C, Rondeau V, Amieva H, Portet F, Dartigues JF, et al. Adherence to a Mediterranean diet, cognitive decline, and risk of dementia. JAMA. 2009;302:638-48.

53. Gu Y, Nieves JW, Stern Y, Luchsinger JA, Scarmeas N. Food combination and Alzheimer disease risk: a protective diet. Arch Neurol. 2010;67:699-706.

54. Scarmeas N, Stern Y, Mayeux R, Manly JJ, Schupf N, Luchsinger JA. Mediterranean diet and mild cognitive impairment. Arch Neurol. 2009;66:216-25.

55. Scarmeas N, Stern Y, Tang MX, Mayeux R, Luchsinger JA. Mediterranean diet and risk for Alzheimer's disease. Ann Neurol. 2006;59:912-21.

56. Trichopoulou A, Costacou T, Bamia C, Trichopoulos D. Adherence to a Mediterranean diet and survival in a Greek population. N Engl J Med. 2003;348:2599-608.
57. Scarmeas N, Luchsinger JA, Schupf N, Brickman AM, Cosentino S, Tang MX, et al. Physical activity, diet, and risk of Alzheimer disease. JAMA. 2009;302:627-37.

58. Scarmeas N, Stern Y, Mayeux R, Luchsinger JA. Mediterranean diet, Alzheimer disease, and vascular mediation. Arch Neurol. 2006;63:1709-17.

59. Scarmeas N, Luchsinger JA, Stern Y, Gu Y, He J, DeCarli C, et al. Mediterranean diet and magnetic resonance imagingassessed cerebrovascular disease. Ann Neurol. 2011;69:25768.

60. Gardener H, Scarmeas N, Gu Y, Boden-Albala B, Elkind MS, Sacco RL, et al. Mediterranean diet and white matter hyperintensity volume in the Northern Manhattan Study. Arch Neurol. 2012;69:251-6.

61. Mosconi L, Murray J, Tsui WH, Li Y, Davies M, Williams S, et al. Mediterranean diet and Magnetic Resonance Imaging-assessed brain atrophy in cognitively normal individuals at risk for Alzheimer's disease. J Prev Alzh dis. 2014;1:1-11.

62. Kalmijn S, Launer LJ, Ott A, Witteman JC, Hofman A, Breteler MM. Dietary fat intake and the risk of incident dementia in the Rotterdam Study. Ann Neurol. 1997;42:776-82.

63. Morris MC, Evans DA, Bienias JL, Tangney CC, Wilson RS. Dietary fat intake and 6-year cognitive change in an older biracial community population. Neurology. 2004;62:1573-9.

64. Morris MC, Evans DA, Tangney CC, Bienias JL, Wilson RS. Fish consumption and cognitive decline with age in a large community study. Arch Neurol. 2005;62:1849-53.

65. Durga J, van Boxtel MP, Schouten EG, Kok FJ, Jolles J, Katan $\mathrm{MB}$, et al. Effect of 3-year folic acid supplementation on cognitive function in older adults in the FACIT trial: a randomised, double blind, controlled trial. Lancet. 2007;369:208-16.

66. Luchsinger JA, Tang MX, Miller J, Green R, Mayeux R. Relation of higher folate intake to lower risk of Alzheimer disease in the elderly. Arch Neurol. 2007;64:86-92.

67. Morris MC, Evans DA, Bienias JL, Tangney CC, Hebert LE, Scherr PA, et al. Dietary folate and vitamin B12 intake and cognitive decline among community-dwelling older persons. Arch Neurol. 2005;62:641-5.

68. Kesse-Guyot E, Andreeva VA, Ducros V, Jeandel C, Julia C, Hercberg S, et al. (2013) Carotenoid-rich dietary patterns during midlife and subsequent cognitive function. Br J Nutr. 1-9.

69. Morris MC, Evans DA, Bienias JL, Tangney CC, Bennett DA, Aggarwal N, et al. Dietary intake of antioxidant nutrients and the risk of incident Alzheimer disease in a biracial community study. JAMA. 2002;287:3230-7.

70. Zandi PP, Anthony JC, Khachaturian AS, Stone SV, Gustafson D, Tschanz JT, et al. Reduced risk of Alzheimer disease in users of antioxidant vitamin supplements: the Cache County Study. Arch Neurol. 2004;61:82-8.

71. Cardoso BR, Cominetti C, Cozzolino SM. Importance and management of micronutrient deficiencies in patients with Alzheimer's disease. Clin Interv Aging. 2013;8:531-42.

72. Doraiswamy PM, Finefrock AE. Metals in our minds: therapeutic implications for neurodegenerative disorders. Lancet Neurol. 2004;3:431-4.

73. Gu Y, Schupf N, Cosentino SA, Luchsinger JA, Scarmeas N. Nutrient intake and plasma beta-amyloid. Neurology. 2012;78: 1832-40.

74.• Mosconi L, Murray J, Davies M, Williams S, Pirraglia E, Spector N, et al. Nutrient intake and brain biomarkers of Alzheimer's in at-risk cognitively normal individuals: a crosssectional neuroimaging pilot study. Br Med J (Open). 2014;4 (6):e004850. This is the first multi-modality brain imaging paper showing associations between nutrient patterns and 3 major brain biomarkers of $A D$ in cognitively normal people (age 25-72 y). 
75. Berti V, Murray J, Davies M, Spector N, Williams S, Pirraglia E, et al. Nutrient patterns and brain biomarkers of Alzheimer's disease in cognitively normal individuals. J Nutrition Health Aging. 2014;2:1-11.

76. Balion C, Griffith LE, Strifler L, Henderson M, Patterson C, Heckman G, et al. Vitamin D, cognition, and dementia: a systematic review and meta-analysis. Neurology. 2012;79:1397-405.

77. Buell JS, Dawson-Hughes B, Scott TM, Weiner DE, Dallal GE, Qui WQ, et al. 25-Hydroxyvitamin D, dementia, and cerebrovascular pathology in elders receiving home services. Neurology. 2010;74:18-26.

78. Bush AI, Pettingell WH, Multhaup G, d Paradis M, Vonsattel JP, Gusella JF, et al. Rapid induction of Alzheimer A beta amyloid formation by zinc. Science. 1994;265:1464-7.

79. Morris MC, Evans DA, Bienias JL, Tangney CC, Bennett DA, Aggarwal N, et al. Dietary fats and the risk of incident Alzheimer disease. Arch Neurol. 2003;60:194-200.

80. Cunnane SC, Plourde M, Pifferi F, Begin M, Feart C, BarbergerGateau P. Fish, docosahexaenoic acid and Alzheimer's disease. Prog Lipid Res. 2009;48:239-56.

81. de Oliveira BF, Veloso CA, Nogueira-Machado JA, de Moraes EN, Santos RR, Cintra MT, et al. Ascorbic acid, alpha-tocopherol, and beta-carotene reduce oxidative stress and proinflammatory cytokines in mononuclear cells of Alzheimer's disease patients. Nutr Neurosci. 2012;15:244-251.

82. Takasaki J, Ono K, Yoshiike Y, Hirohata M, Ikeda T, Morinaga A, et al. Vitamin A has anti-oligomerization effects on amyloid-beta in vitro. J Alzheimers Dis. 2011;27:271-80.

83. Kaczmarczyk MM, Miller MJ, Freund GG. The health benefits of dietary fiber: beyond the usual suspects of type 2 diabetes mellitus, cardiovascular disease and colon cancer. Metabolism. 2012;61: 1058-66.

84. Bowman GL, Shannon J, Ho E, Traber MG, Frei B, Oken BS, et al. Reliability and validity of food frequency questionnaire and nutrient biomarkers in elders with and without mild cognitive impairment. Alzheimer Dis Assoc Disord. 2011;25:49-57.

85. Morris MC, Tangney CC, Bienias JL, Evans DA, Wilson RS. Validity and reproducibility of a food frequency questionnaire by cognition in an older biracial sample. Am J Epidemiol. 2003;158: 1213-7.

86. Willett WC, Sampson L, Stampfer MJ, Rosner B, Bain C, Witschi J, et al. Reproducibility and validity of a semiquantitative food frequency questionnaire. Am J Epidemiol. 1985;122: $51-65$.

87. Bowman GL, Silbert LC, Howieson D, Dodge HH, Traber MG, Frei B, et al. Nutrient biomarker patterns, cognitive function, and MRI measures of brain aging. Neurology. 2012;78:241-9. This paper provides evidence for associations between plasma nutrient patterns, better executive and visuospatial function, larger brain volumes, and lower cerebrovascular burden in the elderly (age $>85$ y).

88. Pottala JV, Yaffe K, Robinson JG, Espeland MA, Wallace R, Harris WS. Higher RBC EPA + DHA corresponds with larger total brain and hippocampal volumes: WHIMS-MRI Study. Neurology. 2014;82:435-42.

89. Samieri C, Maillard P, Crivello F, Proust-Lima C, Peuchant E, Helmer C, et al. Plasma long-chain omega-3 fatty acids and atrophy of the medial temporal lobe. Neurology. 2012;79:642-50.

90. Tan ZS, Harris WS, Beiser AS, Au R, Himali JJ, Debette S, et al. Red blood cell omega-3 fatty acid levels and markers of accelerated brain aging. Neurology. 2012;78:658-64.

91. Bayer-Carter JL, Green PS, Montine TJ, VanFossen B, Baker LD, Watson GS, et al. Diet intervention and cerebrospinal fluid biomarkers in amnestic mild cognitive impairment. Arch Neurol. 2011;68:743-52.

92. Swerdlow RH. Mitochondria and cell bioenergetics: increasingly recognized components and a possible etiologic cause of Alzheimer's Disease. Antioxid Redox Signal. 2011;16:1434-55.

93. Cai W, Uribarri J, Zhu L, Chen X, Swamy S, Zhao Z, et al. Oral glycotoxins are a modifiable cause of dementia and the metabolic syndrome in mice and humans. Proc Natl Acad Sci U S A. 2014;111:4940-5

94. Wyss-Coray T. Inflammation in Alzheimer disease: driving force, bystander or beneficial response? Nat Med. 2006;12:1005-15.

95. Hillman $\mathrm{CH}$, Erickson KI, Kramer AF. Be smart, exercise your heart: exercise effects on brain and cognition. Nat Rev Neurosci. 2008;9:58-65.

96. Stern Y. Cognitive reserve in ageing and Alzheimer's disease. Lancet Neurol. 2012;11:1006-12.

97. Di Marco LY, Marzo A, Munoz-Ruiz M, Ikram MA, Kivipelto M, Ruefenacht D, et al. Modifiable lifestyle factors in dementia: a systematic review of longitudinal observational cohort studies. J Alzheimers Dis. 2014;42:119-35

98. Williams RJ. Biochemical individuality and its implications. Chem Eng News. 1947;26:1112-3.

99. Cooper JK. Nutrition and the brain: what advice should we give? Neurobiol Aging. 2014;35S2:S79-83.

100. Barnard ND, Bush AI, Ceccarelli A, Cooper J, de Jager CA, Erickson KI, et al. Dietary and lifestyle guidelines for the prevention of Alzheimer's disease. Neurobiol Aging. 2014;35S2:S74-8. Seven possible guidelines for Alzheimer's disease prevention emerged, which were related to healthful diet and exercise habits. These guidelines provide a set of practical, albeit preliminary, steps to be recommended to members of the public.

101. Appel LJ, Moore TJ, Obarzanek E, Vollmer WM, Svetkey LP, Sacks FM, et al. A clinical trial of the effects of dietary patterns on blood pressure. DASH Collaborative Research Group. N Engl J Med. 1997;336:1117-24. 